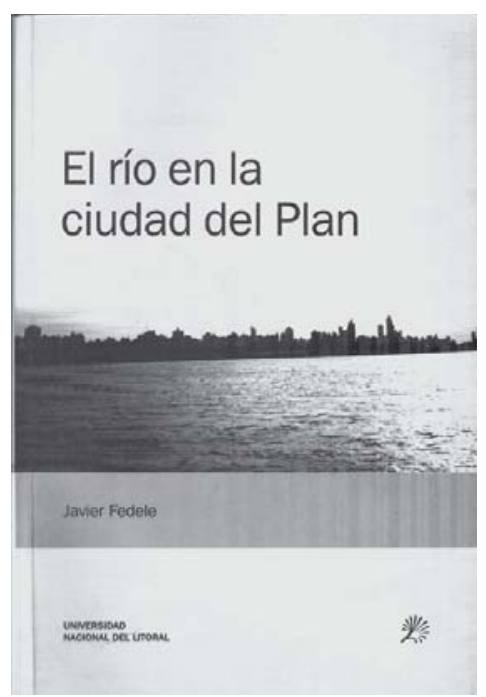

En un momento de la historia de las ciudades y de la práctica del urbanismo argentino, la costa fluvial se volvió tema protagónico. El río en la ciudad del Plan, de Javier Fedele, indaga este núcleo temporal, situado en la primera mitad del siglo $\mathrm{xx}$, alrededor de los años veinte y cuarenta en Argentina, enfocándolo desde las ciudades más importantes de la cuenca de los ríos Plata y Paraná.

A fines del siglo XIX, Argentina presentaba una estructura económica de relativa consolidación territorial. Con el protagonismo del puerto de Buenos Aires, en el que confluían los ferrocarriles, se comenzó a favorecer la región pampeana y el litoral fluvial del río Paraná, punto
EL RÍO EN LA CIUDAD DEL PLAN

\section{Javier Fedele}

Santa Fe: Ediciones, Universidad Nacional del LitORAL, 20 I I

de localización de distintos puertos. La cuenca Plata-Paraná constituyó la vía de navegación más importante del país, tan vital para su desarrollo que el nombre de "litoral" identificó regionalmente a ese territorio en Argentina.

Durante la primera década del siglo xx, las ciudades de mayor desarrollo construyeron modernos puertos sobre el litoral, actualizando las infraestructuras portuarias con el apoyo de una economía que crecía sustentada en el comercio. De esta forma, la costa como unidad espacial comenzó a participar en la planificación urbana, constituyéndose a partir de fragmentados proyectos que empezaban a encontrar coherencia estructural $y$ 
global para la ciudad. En este contexto, los destinos entre río y ciudad comienzan a fundirse en la síntesis del plan urbano, y el rol del borde fluvial en la composición de dicho plan se yergue en un tema de opiniones opuestas. Por un lado, se demandó su uso para las infraestructuras, con actividades económicas monopolizando los litorales en incompatibilidad con programas sociales. Y por otro, se promovieron los sectores costeros como característica territorial del paisaje, como un recurso para la estructuración de espacios cívicos de sociabilidad y cultura urbana. Ambas aspiraciones comenzaron a ser procesadas en los planes, donde se intentaba sistematizar el conflicto y superarlo.

\section{Buenos Aires, 1925}

En el capítulo 1, "La tradición y el paisaje como estrategia insuficiente", se observa cómo desde la ciudad de Buenos Aires surgen las primeras estrategias urbanísticas que fijaron la atención sobre la ribera del río. La costa comenzó a adquirir importancia, mientras el urbanismo va consolidando sus visiones e instrumentos en la instancia sintetizadora del plan.

En Buenos Aires se había avanzado hacia intervenciones de espacios verdes desde las prácticas del paisajismo. La creación de oficinas públicas como la Dirección de Parques y Paseos, con la participación de profesionales extranjeros como Carlos Thays, y sus sucesores locales, como Benito Carrasco, consolidó una forma particular de operar en el espacio urbano. Las iniciativas así surgidas entendieron el borde fluvial como un lugar posible de ser ordenado y potenciado como parque urbano. Esta visión estuvo sujeta a un pasado originario, antes de que la infraestructura portuaria de gran escala mutilara la relación de la ciudad con el Río de la Plata.

En este contexto, Carrasco dio comienzo en 1916 a las obras de la costanera sur, parte de un ambicioso proyecto de costa regional. La inconexión de este resultante nuevo espacio con la estructura urbana consolidada, desdibujado entre instalaciones portuarias y restos de viejas urbanizaciones fracasadas, descubrió la ineficiencia de estas intervenciones, desnudando la necesidad de una escala mayor para alcanzar los objetivos de plantear un parque urbano sobre el río. Se intentó abordar tal propósito mediante un plan, en cuya elaboración se constituyeron en temas centrales de las discusiones y propuestas, la identificación de los usos del lugar y su continuidad con la ciudad.

\section{Santa Fe, 1927}

En el capítulo 2, "El río para la ideación global de la ciudad", se describe cómo el Concejo Deliberante de la Ciudad de Santa Fe aprueba el Proyecto de Urbanización. Este proyecto se configuró como un episodio relevante en la historia de Santa Fe, ya que representó el primer plan urbano de la ciudad y definió líneas estructurales que incidieron en procesos de transformación. Además, trascendió al alcance local, ya que generó una apertura en la génesis del urbanismo en Argentina a partir del rol de ciertos profesionales.

El puerto, ferrocarriles y la costa se transformaron en piezas clave. El plan propuso la ampliación del puerto con el fin de aumentar la zona de maniobras para los barcos y facilitar los accesos ferroviarios, los cuales fueron reordenados en función de eliminar 
conflictos con la trama urbana. La estación del Ferrocarril Santa Fe, primera línea ferroviaria de la ciudad, era un sector escasamente urbanizado aún. En estas instalaciones cercanas al puerto, una vez trasladada su estación, se proyectó un Museo de Ópera y un planetario, a modo de parque de ciencias y artes. Todo ello representó un cambio de actividades relacionadas con el tejido de la ciudad.

El proyecto de urbanización de Santa Fe se constituyó como eslabón entre los planes de embellecimiento y los planes funcionales del zoning. Además de garantizar una ágil accesibilidad, la imagen urbana se fortalecía con una articulación entre el trazado viario y la formalización espacial de las construcciones, en un nuevo sistema de espacios públicos. A través de intervenciones precisas con efectos potentes, se buscaba garantizar la homogeneidad circulatoria y funcional, pero sin menoscabar la centralidad histórica y el valor del río, configuración de un tejido y nueva escala monumental con evidentes referencias al Civic Art de Hegermann.

\section{Rosario, 1935}

En el capítulo 3, "La alternativa científica y estética para apropiarse del río", se analiza un episodio clave que, si bien no logró cambiar la tendencia del conflicto entre las empresas ferroviarias y portuarias con las autoridades municipales, implicó una discusión y sistematización de propuestas urbanísticas. El Plan Regulador y de Extensión de Rosario, de 1935, ajustó una metodología precisa, que definió los componentes de la ciudad y sus vínculos dentro de un sistema de relaciones unificado.
La costa se comprendió como problema científico. Se formó un equipo y se dictó la primera cátedra argentina de urbanismo, donde Ángel Guido, integrante redactor del Plan de Rosario de 1935, fue un personaje relevante. Partícipe del debate académico y profesional de la ciudad, desarrolló una construcción estética del río, enfrentando las ideas que Le Corbusier trajo en 1929. Publicó al respecto La machinolatrie de Le Corbusier, donde estableció un contrapunto irónico con quienes, a nivel local, comenzaban a entusiasmarse con ideas de arquitectura moderna, que consideraba reducida a reglas empobrecidas simbólicamente.

Para Guido, el territorio debía ser el referente para la inspiración. La "emoción territorial" constituía para él un valor que era necesario traducir en forma urbana, la que debía surgir de depurar y enfocar con mayor precisión la "visión actualmente distraída de nuestro paisaje americano: nuestra pampa, nuestra sierra, nuestra costa”. Tras esta orientación estética de lo recónditamente americano, hubo demasiada densidad que Guido siguió recargando, llegando incluso a posiciones reaccionarias en la década de 1940, cuando agudizó su visión identitaria americanista.

Buenos Aires, 1929-1940

El capítulo 4, "L'Esprit Nouveau se vislumbra en el agua", trata el contexto de la visita de Le Corbusier a Argentina, invitado por la Asociación de Amigos del Arte. Esta visita estuvo motivada desde el ámbito del arte más que del urbanismo y la arquitectura. A pesar de ello, las vicisitudes de esta invitación, y las consecuencias que tuvo para el mismo Le Corbusier o para el contexto 
argentino, fueron abordadas en una extensa bibliografía enfocada en este protagonista de la arquitectura del siglo xx. Fue así que Le Corbusier dejó asentadas sus ideas en 1929 para Buenos Aires, las que posteriormente fueron incorporadas en el llamado "Plan director para Buenos Aires", de 1940.

Los ríos impresionaron a Le Corbusier, particularmente el río Paraná y su cuenca junto al Plata. En este contexto, desde su visión estética, proyectó un cuadro purista del Río de la Plata. Sobre su primera visión de la ciudad, extendida a orillas del río, construyó una que podría ser Buenos Aires, lugar predestinado, según él, al fondo del gigantesco estuario. Ya se extendía una ciudad inmensa, con una "cabeza enorme de un cuerpo apenas formado". En este sentido, en el agua estableció una cabecera de una "potente penetración en el hinterland" que transformaría la ciudad, de la que poco importaba en su actual configuración, y que estaba destinada a transformarse desde el río y en su totalidad.

Tal fue el foco del Plan de Buenos Aires de Le Corbusier, la cité d'affaires en el río, donde indicó que "la naturaleza ha aportado este encuentro de la Pampa y del océano, en una línea infinita y llana (...). Buenos Aires, pura creación humana, pura creación del espíritu, bloque inmenso alzado por el hombre, en el agua del río y de pie en el cielo de la Argentina. Hay en esa esperanza algo embriagador, ennoblecedor. ¡Qué incitación!”.

\section{La condición litoral de la ciudad}

Finalmente, en el capítulo 5, "La condición litoral de la ciudad”, se comprende, a modo de síntesis, que la transformación de las ciudades encontró en los planes urbanos un punto de articulación de la estructura socioeconómica, la política $\mathrm{y}$ las tendencias culturales que se fueron sucediendo. Las ciudades fueron modelando sus estructuras a partir del crecimiento y desarrollo de tales procesos, componiendo tradiciones y nuevas demandas en la búsqueda de ordenamiento espacial, siendo las riberas escenario protagónico de estos cambios.

Así surgió la imagen de la "ciudadportuaria”, imagen del urbanismo y de una cultura urbana particular. En el espacio de la costa, la infraestructura ferroportuaria tiene hasta hoy gran protagonismo como elemento de configuración física y de simbolización. La ciudad portuaria, como concepto que interpreta a la ciudad, prefigurando y legitimando una forma de intervenir en ella, se transforma en una tipología de ciudad. Se hace una figura donde quedan correlacionados el funcionamiento de las infraestructuras, el crecimiento urbano, la ocupación de la costa y la dinámica de la estructura tanto física como sociocultural de la ciudad.

El análisis deja entrever que las costas urbanas en Argentina no fueron solo un problema de resolución proyectual, sino un definido proceso histórico estructural de las ciudades. A través de los registros, donde se discutieron las formas en que se construía la ciudad moderna, se indaga en la historia del urbanismo con los planes urbanos como fuente, comprendiendo que en ellos se sintetiza el estado del debate sobre la ciudad. Siendo simultáneamente documentos técnicos y políticos, los planes son comprendidos por el autor como portadores de un conocimiento emanado de 
ámbitos académicos y profesionales, que miden el grado de reconocimiento social de las ideas generadas y su inserción en las instituciones del Estado.

Cabe destacar también cómo este análisis se sitúa en la frontera de la historia urbanística, abriéndose a la heterogeneidad de prácticas y procesos que inciden en la construcción de la ciudad. Los problemas planteados no quedan remitidos exclusivamente al pasado, sino que se proyectan al presente, ya que el tema de cómo abordar urbanísticamente las riberas urbanas es una problemática totalmente vigente. Plantear una reflexión desde la dimensión del tiempo histórico es también un ejercicio de pensamiento para el proyecto actual de ciudad. Si bien en el pasado han quedado problemas irresueltos, propuestas inconclusas o desajustadas al contexto, es posible actualizarlas reflexivamente, no solo por un ejercicio histórico, sino para entender las condiciones sobre las que se opera en la actualidad.

Asimismo, es necesario destacar que las infraestructuras y planes urbanos cambiaron -y siguen cambiando- radicalmente el territorio. En este análisis se da cuenta de conflictos entre infraestructuras ferroportuarias que progresivamente demandaban espacios para el despliegue de sus actividades, y las ciudades que en su rápido crecimiento necesitaban nuevos espacios libres vinculados a la naturaleza. Estos conflictos se siguen entretejiendo en las ciudades contemporáneas, en un entramado que involucra las crecientes capacidades técnicas de transformación del entorno, la movilización de fuerzas sociales y el rol del urbanismo como disciplina. De esta manera, es importante considerar que la evolución articulada de las dimensiones previamente señaladas, determina la transformación de los espacios públicos de la ciudad y de la forma urbana, lo que constituye un proceso relevante para indagar en su historicidad. oEure

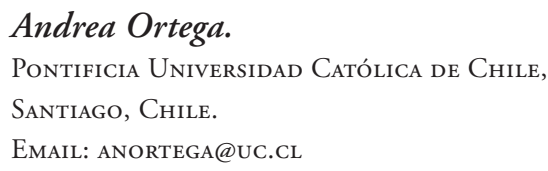

